\title{
New Keynesian Model and Inflation Prediction*
}

\author{
Yutaka Kurihara \\ Aichi University, Nagoya, Japan
}

\begin{abstract}
Recently, much dispute has occurred about the validity of the New Keynesian model from both theoretical and empirical views. However, a few studies have analyzed this model from the empirical perspective. Few other studies have analyzed this model directly or nearly directly. This article empirically examines the New Keynesian model focusing on inflation forecast. Generalized method of moments (GMM) is used to examine whether the typical Keynesian model with Taylor rule is empirically appropriate for the US, UK, Euro area, and Japan. The results showed: (1) the New Keynesian model fits well in most cases and explains the real economy well. Taylor rule also fits well for most cases; (2) Rational expectations for inflation rates may not be useful based on this model. When AR (1) (time series analysis) model is used to capture inflation expectations instead of one-time ahead real values, the model fits well. With measured expectations, the relative weight of the forward-looking terms increase on the cost of lagged inflation and output terms, even up to the point at which the lagged inflation terms are no longer needed to rescue the new Keynesian model; and (3) Forward-looking variables play more important roles than backward-looking ones in economic activity. Results with expectations with forward-looking terms perform better in general. This New Keynesian model may reduce the importance of lagged output in some cases.
\end{abstract}

Keywords: expectation, forward-looking, inflation, New Keynesian, output, Taylor rule

\section{Introduction}

Recently, much dispute has been occurring about the validity of the New Keynesian model not only from the theoretical perspective but from empirically one. However, a few studies have analyzed this model from the empirical perspective (Gnos \& Rochon, 2007). Hall, Hondroiannis, and Tavlas (2009) employed a hybrid open economy model to demonstrate that the United States, United Kingdom, and Canada enjoy less inertia in price setting than the $\mathrm{G} 7$, and showed that models that add lagged inflation and supply shock variables are spurious and miss-specified. Chortareas, Magonis, and Panagiotidis (2012) showed that a pure New Keynesian Phillips curve model accurately captured inflation dynamics at high inflation quantities. Fabio (2012) showed that the conventional estimates co-found two distinct effects on output: "surprise" shocks and "news" on policy shocks. Laurence (2012) employed a revised New Keynesian Phillips curve allowing for entry of firms and increasing competitive pressures with the number of firms. Few other studies, however, have analyzed this model directly or nearly directly.

\footnotetext{
${ }^{*}$ This work is supported by KAKENHI, Japan.

Yutaka Kurihara, Professor, Department of Economics, Aichi University.

Correspondence concerning this article should be addressed to Yutaka Kurihara, Aichi University, 4-60-6 Hiraike Nakamura Nagoya 4538777, Japan. E-mail: kurihara@vega.aichi-u.ac.jp.
} 
Macroeconomists have understood that inflation expectations are an important determinant of inflation. The rational expectation hypothesis states that economic agents' predictions of the future value of relevant variables (e.g., inflation) are not systematically wrong in that all errors are random. This rational expectations assumption is used in many macroeconomic models. Wallusch (2012) showed that average price change probability by the Calvo pricing mechanism was bigger than suggested by the Keynesian Phillips curve literature.

For the inflation expectation, many methods have been employed for empirical analyses. Its importance has recently been the topic of much discussion. For example, Sweidan (2011) proved that the effect of a central bank's inability is larger relative to inflation expectations than the influence of targeted inflation rates. Not only macroeconomic models but also time series analyses are used for inflation forecasting. Recently, Kortelainen, Paloviita, and Viren (2011) used survey-measured expectations for a consensus forecasting. Zhang, Osborne, and Kim (2010) compared the Generalized Method of Moments (GMM) approach and the Survey of Professional Forecasters' data and showed that the output gap performs very poorly and that the survey data results made more sense. Also, the results suggested that lagged inflation is more important to the point at which the coefficient of the expected inflation is hardly significant. Scheufele (2010) found that a model that uses survey expectations outperforms most other competing models. Frédo (2012) also found that survey forecasts improve estimations of the Keynesian Phillips curve. Jean-Baptiste (2012) confirmed that, compared with other estimation methods, survey forecasts improved estimates of the New Keynesian Phillips curve and forecasting performance of inflation.

Luca and Giulio (2011) adopted the New Keynesian Phillips curve in the Euro area and showed that the forward-looking component of inflation expectations is much larger than the backward-looking component. Antonio, Saten, and Bhaskara (2012) showed that backward-looking and forward-looking models are rejected empirically. Emil and Helge (2012) showed that money-based New Keynesian Dynamic Stochastic General Equilibrium (DSGE) models and Vector Autoregressions (VARs) incorporating money perform better than their cashless counterparts. Born, Juessen, and Müller (2013) showed that government spending multipliers are larger under fixed exchange rate regimes and that the New Keynesian model provides a satisfactory explanation of the evidence.

Recent macroeconomic models are generally forward-looking, reflecting an increasing focus on what is coming. There are some possibilities that the hypothesis implies explosions in real variables that are relevant to economic conditions. This article considers the forward-looking model. Because the New Keynesian model contains this variable, it is impossible to avoid this issue to analyze macro economy.

However, this poses additional difficult problems, namely, how to evaluate the data consistency of these models. Since the 1980s, an obvious solution has been the GMM estimator, which basically utilizes the orthogonality conditions of the rational expectations hypothesis. The difference-GMM estimator employs suitable lagged values of the first differences of all endogenous variables as their instruments. GMM is a robust estimator in that, unlike maximum likelihood estimation, GMM does not require information about the exact distribution of the disturbances.

On the other hand, GMM estimates have not been completely satisfactory. Limiting their research to the New Keynesian Model, Bjornland and Leitemo (2011) examined this model by using the Bayesian and Kalman-Filter methods. The purely forward-looking models have been so unsatisfactory that they have been replaced by a hybrid specification in which lagged inflation or output terms have been introduced in a more or 
less ad hoc way. Also, Lanne and Luoto (2013) estimated the New Keynesian model with quarterly U.S. data avoiding the GMM, and both expected future inflation and lagged inflation were found important in determining the inflation rate. Moreover, inflation persistence turned out to be intrinsic.

Although the New Keynesian models provide a theory of endogenous money with exogenous interest rates, these models provide no description of a central bank reaction function (Claude \& Philippe, 2007). This paper examines whether or not the fit of the New Keynesian Model with an assumption of a forward-looking Taylor rule, is good. Lubik and Marzo (2007) showed that when the monetary authority targets output and smoothes interest rates, determinacy is obtained from a wide range of policy parameters. Ramon and Jesus (2008) showed that a generalized version that includes habit formation and a forward-looking Taylor rule can mimic the weak comovement of medium and long-term forecast horizons. Paradiso and Kumar (2013) showed that traditional backward looking and forward looking models are overwhelmingly rejected, however, its evidence supported the extended backward looking model using quadratic trend as output being relevant for monetary policy analysis. However, there has been little empirical study on this issue. Empirical analyses of the New Keynesian model that include these points have not been performed. Finally, Pontiggia (2012) showed that when the traditional New Keynesian model is extended to allow for rule-of-thumb behavior by price setters, the optimality of zero long-run inflation stops, and the monetary authority conducts a positive inflation target.

This article is structured as follows. Section two shows the theoretical model for the empirical analyses. Section three demonstrates the methods of empirical analyses and data employed here. Section four shows the results and the additional analysis is performed. Finally this paper ends with a brief summary.

\section{Theoretical Model}

The model employed here is the following New Keynesian model, which consists of the following three equations:

IS curve:

$$
g a p=a_{1} g a p_{t-1}+\left(1-a_{1}\right) g a p_{t+1}+a_{2}\left(i t-E_{t} \Delta p_{t+1}\right)+\varepsilon_{1 t}
$$

Phillips curve:

$$
\Delta p_{t}=b_{1} \Delta p_{t-1}+\left(1-b_{1}\right) E_{t} \Delta p_{t+1}+b_{2} g a p_{t}+\varepsilon_{2 t}
$$

Taylor rule:

$$
i_{t}=c_{0}+c_{1} \Delta p_{t}+c_{2} g a p_{t}+\varepsilon_{3 t}
$$

where the gap is the output gap (deviation of (log) output $y$ from the equilibrium output $\left(y^{*}\right.$ level)), $i$ is the nominal interest rate, $\Delta p$ is the rate of inflation; $\varepsilon_{1}$ is a demand shock, $\varepsilon_{2}$ is a supply shock, and $\varepsilon_{3}$ is a monetary policy shock. $E$ denotes the mathematical expectations operator.

The Taylor rule may also be estimated in a form such that actual inflation $\Delta p$ is replaced by the expected inflation $E_{t} \Delta p_{t+1}$. This article employs both cases.

\section{Empirical Method and Data}

The estimation methods are GMM and LS (least squared). The GMM estimator proposed by Arellano and Bond (1991) provides consistent estimates for such models. The difference-GMM estimator uses suitable lagged values of the first differences of all endogenous variables as their instruments. It is assumed that current inflation, 
output gap, and interest rates are endogenous and that forecasts of output gap and inflation rate are exogenous. The GMM is a robust estimator, unlike maximum likelihood estimation, in that the GMM does not require information about the exact distribution of the disturbances.

For the inflation forecast, two methods are employed: one uses AR(1) (first-order autoregressive) and rational expectation assumptions. This moving average process affects the properties of the data, possibly violating the orthogonality conditions, but the original data cannot be used directly. The output gap is derived from the Hodrick-Prescott filter from the level form data. This procedure has in fact been used in numerous cases. In the case of the Taylor rule, current and expected inflation rates are both used to demonstrate the implications of forward-looking behavior on estimation results. For interest rates, 3-month rates (interbank interest rates) are used.

The sample period is 1975Q1-2011Q4 and 2000Q1-2011Q4. The Euro was firstly introduced in 1999, so this fact is taken into account.

\section{Estimated Results}

The results are reported in Tables 1 and 2.

Table 1

Estimates of New Keynesian Model (1975Q1-2011Q4)

\begin{tabular}{|c|c|c|c|c|c|c|}
\hline & US & US & Euro & Euro & Japan & Japan \\
\hline & (1) & (2) & (3) & (4) & (5) & (6) \\
\hline$a_{0}$ & $\begin{array}{c}0.352^{* *} \\
(2.301)\end{array}$ & $\begin{array}{c}0.231^{* *} \\
(2.009)\end{array}$ & $\begin{array}{c}0.442^{* *} \\
(2.853)\end{array}$ & $\begin{array}{c}0.082 \\
(0.859)\end{array}$ & $\begin{array}{c}0.099 \\
(0.616)\end{array}$ & $\begin{array}{c}0.081 \\
(0.443)\end{array}$ \\
\hline$a_{1}$ & $\begin{array}{l}0.627^{* * * *} \\
(11.070)\end{array}$ & $\begin{array}{c}0.690^{* * * *} \\
(16.458)\end{array}$ & $\begin{array}{l}0.613^{* * *} \\
(7.904)\end{array}$ & $\begin{array}{c}0.612^{* * * *} \\
(16.24)\end{array}$ & $\begin{array}{c}0.693^{* * *} \\
(11.714)\end{array}$ & $\begin{array}{c}0.579^{* * *} \\
(8.388)\end{array}$ \\
\hline$\left(1-a_{1}\right)$ & 0.373 & 0.310 & 0.387 & 0.388 & 0.307 & 0.411 \\
\hline$a_{2}$ & $\begin{array}{l}-0.043^{*} \\
(-1.843)\end{array}$ & $\begin{array}{l}-0.055^{* *} \\
(-2.534)\end{array}$ & $\begin{array}{l}-0.053^{* * *} \\
(-2.920)\end{array}$ & $\begin{array}{c}-0.047^{*} \\
(-1.736)\end{array}$ & $\begin{array}{c}0.011 \\
(-0.042)\end{array}$ & $\begin{array}{c}-0.033 \\
(-0.598)\end{array}$ \\
\hline$b_{1}$ & $\begin{array}{l}0.133^{* * * *} \\
(22.749)\end{array}$ & $\begin{array}{c}0.057^{* * *} \\
(47.394)\end{array}$ & $\begin{array}{c}0.379^{* * * *} \\
(34.758)\end{array}$ & $\begin{array}{c}0.333^{* * * *} \\
(43.030)\end{array}$ & $\begin{array}{c}0.243^{* * *} \\
(22.359)\end{array}$ & $\begin{array}{c}0.115^{* * * *} \\
(47.869)\end{array}$ \\
\hline$\left(1-b_{1}\right)$ & 0.867 & 0.943 & 0.621 & 0.667 & 0.757 & 0.885 \\
\hline$b_{2}$ & $\begin{array}{l}0.138^{* *} \\
(2.631)\end{array}$ & $\begin{array}{c}0.064^{*} \\
(1.844)\end{array}$ & $\begin{array}{c}-0.071^{* *} \\
(-2.585)\end{array}$ & $\begin{array}{c}0.015 \\
(0.521)\end{array}$ & $\begin{array}{l}0.038^{* * *} \\
(2.918)\end{array}$ & $\begin{array}{c}0.061^{* *} \\
(2.399)\end{array}$ \\
\hline$c_{0}$ & $\begin{array}{l}2.838^{* * * *} \\
(4.248)\end{array}$ & $\begin{array}{l}4.513^{* * *} \\
(9.298)\end{array}$ & $\begin{array}{l}2.305^{* * *} \\
(3.574)\end{array}$ & $\begin{array}{l}2.495^{* * *} \\
(5.904)\end{array}$ & $\begin{array}{c}0.659^{* *} \\
(2.478)\end{array}$ & $\begin{array}{l}1.779^{* * * *} \\
(8.463)\end{array}$ \\
\hline$c_{1}$ & $\begin{array}{l}0.796^{* * *} \\
(6.131)\end{array}$ & $\begin{array}{l}0.648^{* * *} \\
(7.436)\end{array}$ & $\begin{array}{l}3.613^{* * * *} \\
(5.788)\end{array}$ & $\begin{array}{l}0.608^{* * *} \\
(4.613)\end{array}$ & $\begin{array}{l}0.832^{* * *} \\
(7.848)\end{array}$ & $\begin{array}{c}0.981^{* * *} \\
(17.192)\end{array}$ \\
\hline$c_{2}$ & $\begin{array}{c}0.118 \\
(1.466)\end{array}$ & $\begin{array}{c}0.020 \\
(1.418)\end{array}$ & $\begin{array}{l}1.479^{* * *} \\
(4.936)\end{array}$ & $\begin{array}{l}0.385^{* *} \\
(2.384)\end{array}$ & $\begin{array}{c}0.0005 \\
(0.006)\end{array}$ & $\begin{array}{c}-0.038 \\
(-0.503)\end{array}$ \\
\hline Method & GMM & LS & GMM & LS & GMM & LS \\
\hline
\end{tabular}

Notes. Numbers in parentheses are $t$ statistics. ${ }^{* * *}$ denotes significant at $1 \%,{ }^{* *}$ at $5 \%$, and ${ }^{*}$ at $10 \%$ level.

In Tables 1 and 2, the relative weight of lagged term $a_{1}$ is about 0.6 , as in the results from earlier studies (Kortelainen et al., 2011). With expectations, the forward-looking terms become much larger, and the lagged terms become almost unimportant. The coefficients of the real interest rates for the United Kingdom and Japan (equations (5), (6), (9), (10), (13), and (14)) do not make sense. These results are similar to the US cases of Zhang, Osborne, and Kim (2009) and Stracca (2010). As Japanese interest rates have been quite low for a long time, it may have strange effects as equations (5), (6), (13), and (14). As the sample period of UK is short, it may have such results. 
Table 2

Estimates of New Keynesian Model (2000Q1-2011Q4)

\begin{tabular}{lcccccccc}
\hline & US & US & UK & UK & Euro & Euro & Japan & Japan \\
\hline & $(7)$ & $(8)$ & $(9)$ & $(10)$ & $(11)$ & $(12)$ & $(13)$ & $(14)$ \\
\hline$a_{0}$ & $0.128^{* * *}$ & 0.695 & $0.195^{*}$ & 0.054 & $0.537^{* *}$ & 0.058 & $2.518^{*}$ & -0.504 \\
& $(4.128)$ & $(1.264)$ & $(1.840)$ & $(0.405)$ & $(2.590)$ & $(0.359)^{* * *}$ & $(1.871)^{* * *}$ & $(-0.458)^{* * *}$ \\
$a_{1}$ & 0.572 & $0.625^{* * *}$ & $0.595^{* * *}$ & $0.691^{* * *}$ & $0.738^{* * *}$ & $0.778^{* * *}$ & $0.655^{* * *}$ & $0.661^{* * *}$ \\
$\left(1-a_{1}\right)$ & $(1.309)$ & $(12.980)$ & $(14.363)$ & $(10.448)$ & $(9.397)$ & $(10.600)$ & $(10.850)$ & $(7.517)$ \\
$a_{2}$ & 0.428 & 0.375 & 0.405 & 0.309 & 0.262 & 0.222 & 0.345 & 0.339 \\
& $-0.361^{* *}$ & $-0.156^{* *}$ & -0.089 & -0.038 & $-0.328^{* *}$ & -0.179 & 2.524 & 0.878 \\
$b_{1}$ & $(-2.225)^{* * *}$ & $(-1.980)$ & $(-0.892)$ & $(-0.055)$ & $(-1.985)$ & $(-0.012)^{* * *}$ & $(1.174)^{* * *}$ & $(0.557)^{* * *}$ \\
$\left(1-b_{1}\right)$ & $0.869^{* * *}$ & $0.775^{* * *}$ & $0.814^{* * *}$ & $0.999^{* * *}$ & $0.986^{* * *}$ & $0.909^{* * *}$ & $0.501^{* * *}$ & $0.806^{* *}$ \\
$b_{2}$ & $(17.325)$ & $(36.374)$ & $(18.378)$ & $(25.170)$ & $(15.607)$ & $(17.482)$ & $(5.136)$ & $(9.020)$ \\
& 0.131 & 0.225 & 0.186 & 0.001 & 0.014 & 0.091 & 0.499 & 0.194 \\
$c_{0}$ & -0.035 & $0.236^{* *}$ & $0.097^{* *}$ & 0.010 & -0.131 & $0.109^{*}$ & $-0.125^{*}$ & -0.013 \\
& $(-0.475)$ & $(2.466)$ & $(3.176)$ & $(0.333)$ & $(-1.434)$ & $(1.820)$ & $(-1.893)$ & $(-0.193)$ \\
$c_{1}$ & $5.744^{* * *}$ & $1.425^{* * *}$ & $3.622^{* *}$ & $4.528^{* * *}$ & $2.927^{* * *}$ & $0.836^{*}$ & 0.050 & $7.672^{* * *}$ \\
& $(6.853)$ & $(3.357)$ & $(2.736)$ & $(7.212)$ & $(5.457)$ & $(1.807)^{* * *}$ & $(1.520)$ & $\left.(7.024)^{* * *}\right)$ \\
$c_{2}$ & $0.376^{*}$ & $1.068^{* * *}$ & 0.145 & $-0.850^{* *}$ & 0.167 & $0.968^{* * *}$ & 0.017 & $0.119^{* * *}$ \\
Method & $(1.858)$ & $(6.836)$ & $(0.724)$ & $(-2.880)$ & $(0.643)$ & $(4.434)$ & $(0.270)$ & $(9.284)$ \\
\hline
\end{tabular}

Notes. Numbers in parentheses are $t$ statistics. ${ }^{* * *}$ denotes significant at $1 \%,{ }^{* *}$ at $5 \%$, and ${ }^{*}$ at $10 \%$ level.

Zhang et al. (2009) showed that prices are more rigid in Europe and that the interest rate sensitivity of the IS curve in Europe (recent period as in Table 2) is more pronounced, which may indicate that the interest rate channel is more important. The results here show such situations as equations (3), (4), (11), and (12).

For the Taylor rule, the fit is pretty good for most cases except for the United Kingdom (equations (9) and (10)). Monetary authorities react to inflation but only weakly react to the output gap as Cem (2012).

The important results are forward-looking terms. Instead of AR(1), data derived from using assumptions of rational expectations are analyzed. The results are as show in Table 3.

Table 3

Estimates of New Keynesian Model in the Case of Rational Expectations (2000Q1-2011Q4)

\begin{tabular}{clllllllll}
\hline & US & US & UK & UK & Euro & Euro & Japan & Japan \\
\cline { 2 - 10 } & $(1)$ & $(2)$ & $(3)$ & $(4)$ & $(5)$ & $(6)$ & $(7)$ & $(8)$ \\
\hline \multirow{2}{*}{$c_{I}$} & -0.311 & -0.190 & 0.373 & $-0.814^{* *}$ & 0.324 & 0.771 & 0.034 & 0.099 \\
& $(-0.560)$ & $(-0.377)$ & $(1.325)$ & $(-2.558)$ & $(0.448)$ & $(1.023)$ & $(0.154)$ & $(1.204)$ \\
\hline
\end{tabular}

Notes. Numbers in parentheses are $t$ statistics. ${ }^{* *}$ denotes significant at $5 \%$.

Almost all of the variables except equation (4) are not significant compared with the cases of AR(1). The variables do not show effective explanation variables.

\section{Conclusions}

Estimation results make sense for the Euro area and for the United States. Results with expectations with forward-looking terms perform better.

Results with AR(1) inflation expectations instead of rational expectations perform better, but the most 
important observation deals with the role of forward-looking terms in the model. With measured expectations, the relative weight of the forward-looking terms increase on the cost of lagged inflation and output terms, even up to the point at which the lagged inflation terms are no longer needed to rescue the new Keynesian model with additional elements.

Further research is needed. Mazumder (2011) casted doubt on the empirical viability of the New Keynesian Phillips curve model. The empirical evidence on this is far from conclusive. For example, the marginal cost DSGE model estimation would be interesting. Also, it would be interesting to compare other models. It would be necessary to divide the time period (Liu \& Jansen, 2011; Oliver \& Yuriy, 2011). For the cases of the EU area, some time is needed to analyze this situation in greater depth.

\section{References}

Antonio, P., Saten, K., \& Bhaskara, R. B. (2012). A new Keynesian IS curve for Australia: Is it forward looking or backward looking? MPRA, 9, 1-22.

Arellano, M., \& Bond, S. (1991). Some tests of specification for panel data: Monte Carlo evidence and an application to employment equations. Review of Economic Studies, 58(2), 277-297.

Bjornland, H., \& Leitemo, K. (2011). Estimating the natural rates in a simple new Keynesian framework. Empirical Economics, 40(3), 755-777.

Born, B., Juessen, F., \& Müller, G. J. (2013). Exchange rate regimes and fiscal multipliers. Journal of Economic Dynamics \& Control, 37(2), 446-465.

Cem, C. (2012). The interaction between monetary and fiscal policies in Turkey: An estimated new Keynesian DSGE model. Economic Modelling, 29(4), 1258-1267.

Chortareas, G., Magonis, G., \& Panagiotidis, T. (2012). The asymmetry of the new Keynesian Phillips curve in the Euro-area. Economics Letters, 114(2), 161-164.

Claude, G., \& Philippe, R. (2007). The new consensus and post-Keynesian interest rate policy. Review of Political Economy, 19(3), 369-386.

Emil, S., \& Helge, B. (2012). The information content of money in forecasting Euro area inflation. Applied Economics, 44(1), 4055-4057.

Fabio, M. (2012). Has has globalization transformed U.S. macroeconomic dynamics? Macroeconomic Dynamics, 16(2), $204-229$.

Frédo, J. B. (2012). Forecasting with the new Keynesian Phillips curve: Evidence from survey data. Economics Letters, 117(3), 811-813.

Gnos, C., \& Rochon, L. (2007). Monetary policy and financial stability: A post-Keynesian agenda. UK: Edward Elgar.

Hall, S., Hondroiannis, D., \& Tavlas, S. (2009). Bretton-Woods systems, old and new, and the rotation of exchange-rates regimes. Discussion Paper in Economics 09/15.

Jean-Baptiste, F. (2012). Forecasting with the new Keynesian Phillips curve: Evidence from survey data. Economics Letters, 117(3), 811-813.

Kortelainen, M., Paloviita, M., \& Viren, M. (2011). Observed inflation forecasts and the new Keynesian macro model. Economics Letters, 112(1), 88-90.

Lanne, M., \& Luoto, J. (2013). Autoregression-based estimation of the new Keynesian Phillips curve. Journal of Economic Dynamics \& Control, 37(3), 561-570.

Laurence, B. (2012). Product market regulation, trend inflation and inflation dynamics in the new Keynesian Phillips curve. Economic Modelling, 29(5), 2058.

Liu, D., \& Jansen, D. (2011). Does a factor Phillips Curve help? An evaluation of the predictive power for U.S. inflation. Empirical Economics, 40(3), 807-826.

Lubik, T., \& Marzo, A. (2007). An inventory of simple monetary policy rules in a new Keynesian macroeconomic models. International Review of Economics and Finance, 16(1), 25-46.

Luca, F., \& Giulio, P. (2011). Simulation based tests of forward-looking models under UAR learning dynamics. Journal of Applied Econometrics, 26(5), 762-775. 
Mazumder, S. (2011). The empirical validity of the new Keynesian Phillips curve using survey forecasts of inflation. Economic Modelling, 28(6), 2439-2452.

Oliver, C., \& Yuriy, G. (2011). Monetary policy, trend inflation, and the great moderation: An alternative interpretation. The American Economic Review, 101(1), 341-370.

Paradiso, A., \& Kumar, S. (2013). A new Keynesian IS curve for Australia: Is it forward looking or backward looking? Applied Economics, 45(26), 3691-3700.

Pontiggia, D. (2012). Optimal long-run inflation and the new Keynesian model. Journal of Macroeconomics, 34(4), $1077-1094$.

Ramon, M. D., \& Jesus, V. (2008). The new Keynesian monetary model: Does it show the comovement between GDP and inflation in the U.S. Journal of Economic Dynamics and Control, 32(5), 1466-1480.

Scheufele, R. (2010). Are qualitative inflation expectations useful to predict inflation? Journal of Business Cycle Measurement and Analyses, 1(1), 29-53.

Stracca, L. (2010). Is the new Keynesian IS curve structural? (pp. 1-45). ECB Working Paper Series No. 1236.

Sweidan, O. (2010). Central bank losses: Causes and consequences. Asian-Pacific Economic Literature, 25(1), 29-42.

Wallusch, J. (2012). How frequently do consumer prices change in transition countries. Applied Economics Letters, 19(10), 921-923.

Zhang, C., Osborne, D., \& Kim, D. (2009). Observed inflation and the new Keynesian Phillips curve. Oxford Bulletin of Economics and Statistics, 71(3), 375-398. 